\title{
PERSPECTIVE
}

\section{SGIM-AMDA-AGS Consensus Best Practice Recommendations for Transitioning Patients' Healthcare from Skilled Nursing Facilities to the Community}

\author{
Lee A. Lindquist, MD MPH MBA' , Rachel K. Miller, MD², Wayne S. Saltsman, MD PhD CMD³, \\ Jennifer Carnahan, MD MPH' , Theresa A. Rowe, DO', Alicia l. Arbaje, MD MPH ${ }^{5}$, Nicole Werner, $P h D^{6}$, \\ Kenneth Boockvar, $M D^{7,8,9}$, Karl Steinberg, $M D C M D^{10}$, and Shahla Baharlou, $\mathrm{MD}^{7}$
}

\begin{abstract}
'Division of General Internal Medicine and Geriatrics, Northwestern University Feinberg School of Medicine, Chicago, IL, USA; ${ }^{2}$ Division of Geriatric Medicine, University of Pennsylvania School of Medicine, Philadelphia, PA, USA; ${ }^{3}$ Lahey Hospital and Medical Center, Burlington, MA, USA; ${ }^{4}$ Indiana University Center for Aging Research, Regenstrief Institute, Inc., Indianapolis, IN, USA; 5 Johns Hopkins University Division of Geriatric Medicine and Gerontology, Baltimore, MD, USA; 'Department of Industrial and Systems Engineering, University of Wisconsin-Madison, Madison, WI, USA; ${ }^{7}$ Brookdale Department of Geriatrics and Palliative Medicine, Icahn School of Medicine at Mount Sinai, New York, NY, USA; ${ }^{8}$ Geriatrics Research Education and Clinical Center, James J Peters VA Medical Center, Bronx, NY, USA; ${ }^{2}$ Research Institute on Aging, The New Jewish Home, New York, NY, USA; ${ }^{10}$ California State University Institute for Palliative Care, San Marcos, CA, USA.
\end{abstract}

We assembled a cross-cutting team of experts representing primary care physicians (PCPs), home care physicians, physicians who see patients in skilled nursing facilities (SNF physicians), skilled nursing facility medical directors, human factors engineers, transitional care researchers, geriatricians, internists, family practitioners, and three major organizations: AMDA, SGIM, and AGS. This work was sponsored through a grant from the Association of Subspecialty Physicians (ASP). Members of the team mapped the process of discharging patients from a skilled nursing facility into the community and subsequent care of their outpatient PCP. Four areas of process improvement were identified, building on the prior work of the AMDA Transitions of Care Committee and the experiences of the team members. The team identified issues and developed best practices perceived as feasible for SNF physician and PCP practices to accomplish. The goal of these consensus-based recommended best practices is to provide a safe and high-quality transition for patients moving between the care of their SNF physician and PCP.

J Gen Intern Med 32(2): 199-203

DOI: $10.1007 / \mathrm{s} 11606-016-3850-8$

(c) Society of General Internal Medicine 2016

$\mathrm{W}$ hile care transitions have become a target for reform efforts, our current understanding of how to optimize care transitions for patients remains incomplete. ${ }^{1}$ Transitional care is defined as a set of actions designed to ensure coordination and continuity of healthcare as patients transfer between different locations or different care levels within the same location. ${ }^{2}$ Much of transitional care research and improvement efforts have focused on the process of hospital

Received April 25, 2016

Revised July 21, 2016

Accepted August 15, 2016

Published online October 4, 2016 discharge to home..$^{3-6}$ The skilled nursing facility (SNF)-tohome transition is an equally important transition which has been largely neglected in the care transition discussions. ${ }^{7}$ Patients transferred from a hospital to an SNF and then home are at increased risk of complications because of multiple transitions (e.g., at least two transitions as opposed to directly home). Additionally, patients requiring SNF stay are generally more medically complex and thus at greatest risk for complicated care transitions. ${ }^{8}$ Over 1.5 million older adults aged $\geq$ 65 years receive care in a subacute SNF for rehabilitation and/ or custodial care each year, and the use of SNFs for rehabilitation is increasing. ${ }^{9,}{ }^{10}$ With the average SNF stay per Medicare admission at 25.9 days, many hospital systems are being penalized for rehospitalization of patients who receive care at SNFs in the 30-day period post-hospital discharge. ${ }^{11}$ Research has shown that $24 \%$ of patients in SNFs were readmitted to a hospital within 30 days of discharge, costing Medicare \$4.3 billion in 2006 alone. ${ }^{12-14}$ Beyond financial penalties, when a patient is transitioned, there are clinical complexities that fail to be transmitted between SNF physician and primary care provider $(\mathrm{PCP}) .{ }^{15}$ Primary care providers frequently have limited or no knowledge of what has happened to their patient while at the SNF. SNF physicians face barriers in identifying the correct PCP and transmitting information. Ultimately, the care of the older adult patient is jeopardized. ${ }^{16}$ In addition, there is significant variability in how often a patient in an SNF is seen by a medical provider. According to the Centers for Medicare \& Medicaid Services (CMS), a provider must see a patient within $72 \mathrm{~h}$ of admission to an SNF, but only within 30 days thereafter. Some patients are seen daily or weekly by providers, while other patients may not be seen for weeks. Thus, a SNF physician may have only 1-2 visits with a patient in a SNF prior to discharge, leading to significant variability in the discharge process.

In response to this knowledge gap in the SNF-to-home transition, the Geriatrics Task Force of the Society of General Internal Medicine (SGIM) assembled a team of physicians from across 
the nation who practice in outpatient primary care, SNFs, and home settings. In addition, a human factors engineer was invited to provide an interdisciplinary perspective and assistance with the flow processes. The purpose of this working group was to identify best practice recommendations for optimal healthcare transitions from SNF to home. Understanding that both SNF physicians and PCPs must work together in the transition of patients between SNF and home, we engaged AMDA-The Society for Post-Acute and Long-Term Care Medicine (formerly known as the American Medical Directors Association), which comprises providers who primarily serve patients in SNFs. Because patients who receive care in SNFs are mostly older adults, we also engaged the American Geriatrics Society (AGS) in order to expand the breadth of geriatrics knowledge that is essential in this transition. Representative members from SGIM, AGS, and AMDA were present at the consensus meeting and had an integral role in developing the best practices. The working group was facilitated by a geriatrician and SNF medical director. Members of the group initially mapped the SNF-to-home information transfer that occurs during the transition (Fig. 1). Through this mapping, the group was able to identify the main points where providers and patients exchange information and openly discuss concerns and priorities for the SNF-to-PCP transition. The facilitator identified areas of agreement/disagreement, and then further discussion was held with the entire group until consensus regarding proposed best practices was reached. With each identified issue, we developed best practices presented in this article that address the responsibilities of both SNF physician and PCP.

\section{POLICY IMPLICATIONS AND FUTURE RESEARCH}

As our population ages, the number of transitions of care from SNF to home will increase significantly. CMS has acknowledged this, and in their proposed rule, Reform of Requirements for Long-Term Care Facilities ( $\$ 483.20$ ), recommend that in addition to documentation of the transition and/or discharge from nursing facilities, specific patient information be exchanged with the receiving provider (e.g., PCP). ${ }^{17} \mathrm{How}-$ ever, they do not further specify how the communication should occur or require a specific format. Adoption of the recommendations listed below will potentially provide a foundation for requirements that facilities must meet as part of CMS's conditions of participation. In addition, these recommendations provide clinicians and health services researchers a unique opportunity to further study how these best practices impact clinical care and can effectively be implemented.

\section{ISSUE \# 1: THE PCP DOES NOT REALIZE THAT THE PATIENT IS ADMITTED TO THE SNF.}

Responsibilities:

SNF physician: Identify the correct community PCP.

PCP: Confirm and update PCP information and fields in charts.
When patients are transitioned from hospital to SNF, hospital records may list an incorrect PCP or may not reference a PCP at all. As a result, on discharge from the SNF, the SNF discharge information may be sent to the incorrect PCP's office, and patients may be instructed to follow up with a PCP whom they have not seen or no longer see. Research has shown that about $20 \%$ of patients receiving care in an SNF indicated having no PCP, and another $20 \%$ provided an unusable name (e.g., not found in any directory or license was expired). ${ }^{18,}{ }^{19}$ It is our recommendation that upon admission to an SNF, all possible measures be taken to identify the correct PCP. Multiple SNF personnel can work to identify the PCP. The admissions coordinator, admitting floor nurse, case manager, or SNF Physician can speak directly to the patient or family to confirm the PCP upon admission. In some scenarios, a patient may see multiple PCPs or may be transitioning between PCPs, which is not ideal but does occur (e.g., patient seeing a Veterans Administration (VA) PCP for medications and a non-VA PCP for preventive care). SNF staff may find it beneficial to ask the patient or family which PCP they would like to have updated on their care and follow-up with at discharge, similar to a "point person" in discussions with multiple family members. In cases where the patient does not have a PCP, discovering the lack of PCP on admission would allow time for SNF staff to identify a potential PCP or community clinic provider during the SNF admission, to ensure appropriate follow-up on discharge.

Correspondingly, PCPs can assist in the identification of patients. From a PCP viewpoint, PCPs who use electronic medical records may delay updating the primary provider field due to time constraints when seeing a new patient. Annually, PCPs may consider obtaining a list of their patients who identify them as PCPs and confirm this information. Staff may be able to review lists using the criterion that patients have been seen within an allotted time frame (e.g., last 2 years). The goal is to enable identification of the correct PCP or to establish care with a new PCP so that patients have adequate follow-up after discharge from an SNF.

\section{ISSUE \#2: DELAY OR LACK OF PATIENT FOLLOW-UP WITH PCP AFTER SNF DISCHARGE.}

Responsibilities:

SNF physician: Schedule a follow-up appointment with the PCP within 7 days post-discharge from SNF.

PCP: Expedite scheduling of patients being discharged from a SNF.

The timing of the follow-up appointment is important. Evidence has shown that patients who follow up promptly with their PCPs after a hospitalization have improved outcomes, including fewer medication errors. ${ }^{20-23}$ In an effort to reduce length of stay (LOS) and adverse events in the hospital, 


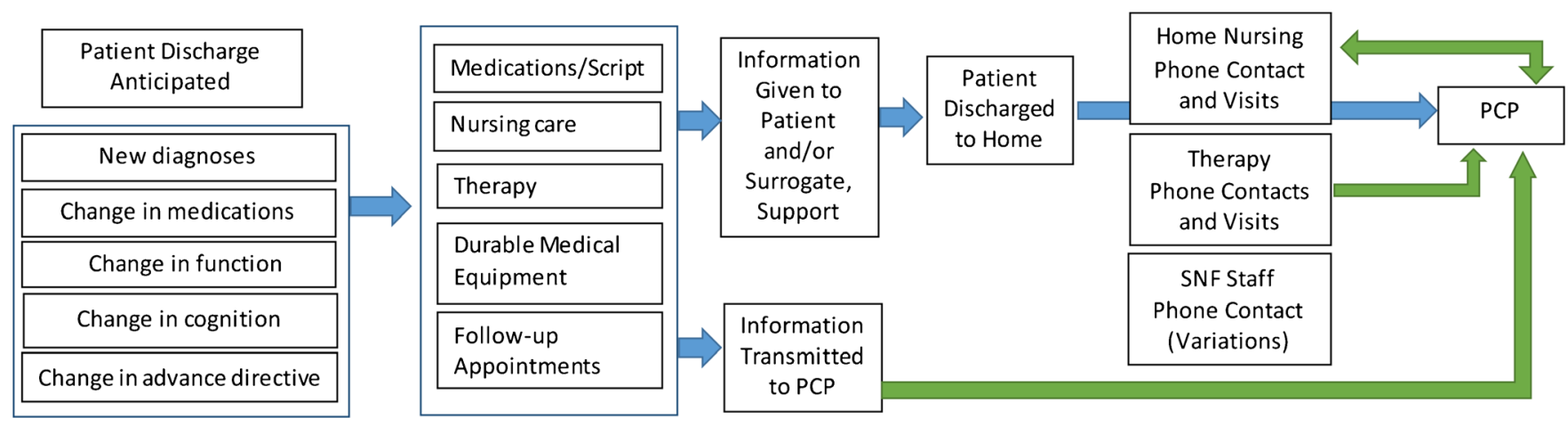

Fig. 1 SNF-to-home transition process map.

SNF physicians are being asked to provide care for more acutely ill patients. ${ }^{24}$ Essentially, SNFs are becoming stepdown hospitals. As complexity of care increases in the SNF, the majority of patients being discharged from an SNF need the same close follow-up as those discharged from a hospital. We recognize that some may argue that certain patients may not require close follow-up (e.g., elective joint replacement). It is our belief that close follow-up of patient status post-joint replacement is warranted for eliminating unnecessary medications, for medication reconciliation (especially with formulary differences) and management of pain, and for reducing the number of emergency department visits. Similar to expedited appointments for patients discharged from hospitals, ${ }^{25}$ patients being discharged from SNFs need to have appointments expedited. Instructions should be given to office staff that patients being discharged from SNFs should be scheduled within 7 days of discharge, and for some patients it may be even sooner. Protocols for situations in which PCPs have limited or no availability should be developed according to personal practice preferences (e.g., seeing alternate providers, overbooking).

\section{ISSUE \#3: THE PCP DOES NOT RECEIVE INFORMATION PERTAINING TO THE PATIENT'S CARE AT THE SNF OR} RECOMMENDED FOLLOW-UP.

Responsibilities (a):

SNF physician: Transmit discharge instructions to the PCP office at time of patient discharge from the SNF and a formal discharge summary to the PCP prior to the followup appointment or within 72 hours of discharge from SNF, whichever comes first.

PCP: Read, follow-up, and include information from the SNF physician in the outpatient medical record.

Regardless of practice location, providers require accurate and timely data in order to provide high-quality patient care. ${ }^{26}$ A concise discharge summary from the SNF Physician is an integral component in a PCP's ability to provide optimal care to patients. AMDA has developed a table of key elements for a discharge summary, which is available online. ${ }^{27}$ In addition, the inclusion of the contact information for the SNF Physician and knowledgeable SNF staff would be useful in the event that further questions arise.

In addition to completion of the discharge summary, delivery of the discharge summary to the PCP is vital. Research has shown that hospital discharge summaries are available at only 12 to $34 \%$ of post-discharge physician visits, and there is little reason to expect higher rates from SNF discharges. ${ }^{28}$ Oftentimes, issues arise between the moment the patient is discharged from the SNF and when the discharge summary is completed. Patient discharge instructions can provide information to the PCP on medications that were prescribed, home health instructions, and follow-up information. Having even this information available when a patient or family member calls can be useful in caring for the patient. Options for delivery can include faxing to the PCP office and electronic delivery through a secure EHR or server. A common practice in the SNF is to give the discharge instructions to the resident or family, with directions to share it with the PCP at the time of their follow-up appointment. This method should be considered mainly as a backup to the other direct delivery methods, with the understanding that it may be less effective for frail or cognitively impaired patients, since they may not reliably remember to take the discharge forms to their appointment.

\section{Responsibilities (b):}

SNF physician: Verbal report given by SNF nurse and/ or physician.

PCP: Prepare outpatient staff for reception of verbal report from SNF staff.

When patients are transferred between settings (e.g., hospital to SNF, hospital floor to ICU), it is routine practice for nurses and/or physicians to "give report" to the receiving parallel nurses and/or PCPs. As patients are transferred from SNF to PCP care, it would be feasible to have the SNF nurse contact the PCP nurse or care manager to give report as standard practice. With patients who are medically complex, it is reasonable for the SNF physician to attempt to contact the PCP directly (a "warm handoff" or "warm hand-over"). This verbal report enables communication of critical information, follow-up needs, care plans, and questions/answers to be transferred. When information is being transmitted during 
Table 1 SNF-PCP Transitional Care Issues and Best Practice Process Improvement Recommendations

\begin{tabular}{|c|c|c|}
\hline \multirow{2}{*}{$\begin{array}{l}\text { SNF-PCP Transition } \\
\text { Issue }\end{array}$} & \multicolumn{2}{|c|}{ Best Practice Recommendations } \\
\hline & SNF & PCP \\
\hline $\begin{array}{l}\text { Issue \#1: PCP does } \\
\text { not realize that patient } \\
\text { is admitted to SNF. }\end{array}$ & $\begin{array}{l}\text { Identify the correct } \\
\text { community PCP and } \\
\text { include identity in } \\
\text { SNF chart. }\end{array}$ & $\begin{array}{l}\text { Confirm and update } \\
\text { PCP information } \\
\text { and fields in charts. }\end{array}$ \\
\hline $\begin{array}{l}\text { Issue \#2: Patient does } \\
\text { not follow up or } \\
\text { delays follow-up with } \\
\text { PCP after SNF dis- } \\
\text { charge. }\end{array}$ & $\begin{array}{l}\text { Schedule a follow-up } \\
\text { appointment with } \\
\text { PCP within } 7 \text { days } \\
\text { post-discharge from } \\
\text { SNF. }\end{array}$ & $\begin{array}{l}\text { Expedite scheduling } \\
\text { of patients being } \\
\text { discharged from an } \\
\text { SNF. }\end{array}$ \\
\hline $\begin{array}{l}\text { Issue \#3: Information } \\
\text { on care received at } \\
\text { SNF and future } \\
\text { necessary follow-up is } \\
\text { not received by PCP } \\
\text { and outpatient team. }\end{array}$ & $\begin{array}{l}\text { Transmit discharge } \\
\text { instructions to the } \\
\text { PCP office at time of } \\
\text { patient discharge and } \\
\text { a formal discharge } \\
\text { summary within } 72 \mathrm{~h} \\
\text { of discharge. }\end{array}$ & $\begin{array}{l}\text { Read, follow up, } \\
\text { and include } \\
\text { information from the } \\
\text { SNF physician in } \\
\text { the outpatient } \\
\text { patient record. }\end{array}$ \\
\hline & $\begin{array}{l}\text { Verbal report is given } \\
\text { by SNF nurse and/or } \\
\text { physician. }\end{array}$ & $\begin{array}{l}\text { Prepare outpatient } \\
\text { staff for receipt of } \\
\text { verbal report from } \\
\text { SNF staff. }\end{array}$ \\
\hline $\begin{array}{l}\text { Issue \#4: Upon return } \\
\text { home, patient has } \\
\text { questions, faces } \\
\text { inaccurate medication } \\
\text { reconciliation, or does } \\
\text { not receive vital } \\
\text { services. }\end{array}$ & \multicolumn{2}{|c|}{$\begin{array}{l}\text { Ensure patient receives a phone call } 48 \mathrm{~h} \\
\text { following SNF discharge. }\end{array}$} \\
\hline
\end{tabular}

the nurse-to-nurse handoff, the outpatient nurse may need to be primed to anticipate calls from SNF nursing staff and trained on what to do with the information received. PCPs may need to discuss protocols on handling the SNF verbal report. It is useful to enter this verbal report into the patient's medical record as: (1) time and date call occurred, (2) contact information of caller/SNF site, (3) pertinent information received such as medications changed, and (4) follow-up expectations (e.g., labs, appointments needed).

\section{ISSUE \#4: UPON RETURN HOME, PATIENT HAS REMAINING QUESTIONS, FACES INACCURATE MEDICATION RECONCILIATION (E.G., RETURNS TO OUTPATIENT MEDICATION LIST), OR DOES NOT RECEIVE VITAL SERVICES (E.G., DME, HOME HEALTH, THERAPY).}

\section{Responsibilities:}

SNF physician and PCP: Ensure patient receives a phone call within 48 hours following SNF discharge.

There are multiple programs in effect that utilize a 48 -h post-SNF discharge telephone contact. ${ }^{29}$ SNF staff may already call patients for satisfaction surveys and to answer any questions that may have arisen. Home health nursing may contact patients during this time to establish visit times. PCP offices may contact patients to fulfill the requirements of transitional code billing. A concern from our expert group was that many parties are contacting patients, which may be frustrating or confusing, although this concern was tempered by the consideration that issues would be uncovered sooner and would not fall through the cracks. It was the consensus of the group that upon discharge, the SNF staff member who explained the discharge instructions (e.g., touched the patient last) and knew the patient would be the ideal person to perform the phone call. This may be a nurse, social worker, case manager, or discharge coordinator at the SNF. There should also be a backup system in the event that the person initiating the phone call is unavailable (e.g., nurse unavailable at the time of discharge).

For PCPs interested in performing the call, the transitional code for billing may help support the staff time. The phone call should be an expectation for patients. Prior to the patient leaving the SNF and when explaining the discharge instructions, SNF staff may find it helpful to arrange for a time to call the patient and to convey the "appointment time" for the phone call. The contents of the phone call may vary, but at a minimum should check that medications were obtained, assess for changes in symptoms, ascertain that services were received, and field questions that may have arisen on the transition home.

\section{CONCLUSIONS}

It is the goal of this workgroup to present a set of actionable items that can be implemented in a daily workflow among both SNF physicians and PCPs to improve the care of our patients as they transition from SNF to home. The recommendations are summarized in Table 1 . We recommend that, in the interest of providing high-quality care, both PCPs and SNFs adopt these best practices in order to serve their patients and referring providers. Our goal across all settings and transitions is to provide the framework for patients to receive high-quality care throughout the entire healthcare system. Without adequate guidance on this important transition, not only do SNFs and hospital systems suffer financial costs, but patients will continue to circulate through the healthcare cycle of unnecessary and burdensome hospital admissions and readmissions.

Acknowledgments: The development of this manuscript was supported by the Society of General Internal Medicine and grant funding from the Association of Subspecialty Physicians. The SGIM Council, AMDA, and AGS have reviewed this manuscript and support the statements and recommendations. We appreciate the assistance of Kay Ovington, Leslie Dunne, and Shana Donchatz in this project. These consensus best practice recommendations were presented at the 2016 annual meetings of AMDA, AGS, and SGIM.

Corresponding Author: Lee A. Lindquist, MD MPH MBA; Division of General Internal Medicine and Geriatrics, Northwestern University Feinberg School of Medicine, 750 North Lake Shore Drive - 10th floor, Chicago, IL 60611, USA (e-mail: LALA25@md.northwestern.edu).

\section{Compliance with ethical standards:}

Conflict of interest: The authors declare no conflicts of interest. 


\section{REFERENCES}

1. Arbaje AI, Kansagara DL, Salanitro AH, Englander HL, Kripalani S, Jencks SF, Lindquist LA. Regardless of age: Incorporating principles from geriatric medicine to improve care transitions for patients with complex needs. J Gen Intern Med. 2014;29(6):932-9.

2. Coleman EA, Boult C. Improving the quality of transitional care for persons with complex care needs. J Am Geriatr Soc. 2003;51:556-557.

3. Jack BW, Chetty VK, Anthony D, et al. A reengineered hospital discharge program to decrease rehospitalization: a randomized trial. Ann Intern Med. 2009; 150(3): 178-187.

4. Naylor MD, Brooten D, Campbell R, et al. Comprehensive discharge planning and home follow-up of hospitalized elders: a randomized clinical trial. JAMA. 1999;281(7):613-620.

5. Hansen LO, Greenwald JL, Budnitz T, et al. Project BOOST: effectiveness of a multihospital effort to reduce rehospitalization. J Hosp Med. 2013;8(8):421-427.

6. Coleman EA, Mahoney E, Parry C. Assessing the quality of preparation for posthospital care from the patient's perspective: the care transitions measure. Med Care. 2005;43(3):246-255

7. Guinn CC, Port CL, Zimmerman S, Gruber-Baldini AL, Kasper JD, Fleshner I, Yody B, Loome J, Magaziner J. Short-Stay Nursing Home Rehabilitation Patients: Transitional Care Problems Pose Research Challenges. J Am Geriatr Soc. 2008;56:1940-1945.

8. Coleman EA, Min SJ, Chomiak A, Kramer AM. Posthospital care transitions: patterns, complications, and risk identification. Health Serv Res. 2004;39(5):1449-1465.

9. Skilled Nursing Facility Services - Centers for Medicare and Medicaid Services. http://medpac.gov/documents/reports/chapter-8-skilled-nursing-facility-services-(march-2015-report).pdf. Accessed July 18, 2016.

10. Wells JL, Seabrook JA, Stolee P, et al. State of the art in geriatric rehabilitation. Part II: Clinical challenges. Arch Phys Med Rehabil. 2003;84:898-903.

11. Centers for Medicare \& Medicaid Services, Office of Information Services. Data from the Medicare Decision Support Access Facility: Office of Research, Development, and Information [on-line]. Available at http:// www.cms.hhs.gov/DataCompendium/17_2007Data_Compendium. asp\#TopOfPage. Accessed July 18, 2016.

12. Grabowski DC, O'Malley AJ, Barhydt NR. The costs and potential savings associated with nursing home hospitalizations. Health Aff (Millwood). 2007;26(6):1753-1761

13. Mor V, Intrator $\mathbf{O}$, Feng $\mathbf{Z}$, Grabowski DC. The revolving door of rehospitalization from skilled nursing facilities. Health Aff (Millwood). 2010;29(1):57-64.

14. Kramer A, Eilertsen T, Lin M, Hutt E. Effects of nurse staffing on hospital transfer quality measures for new admissions. In: Appropriateness of minimum nurse staffing ratios for nursing homes. Baltimore: Health Care Financing Administration; 2000:9.1-9.22.

15. Kripalani S, LeFevre F, Phillips CO, et al. Deficits in communication and information transfer between hospital-based and primary care physicians:
Implications for patient safety and continuity of care. JAMA. 2007;297(8):831-841.

16. Coleman E, Berenson R. Lost in Transition: Challenges and Opportunities for Improving the Quality of Transitional Care. Ann Intern Med. 2004; 141(7):533-536

17. Medicare and Medicaid Programs; Reform of Requirements for Long-Term Care Facilities. https://www.federalregister.gov/articles/2015/07/16/ 2015-17207/medicare-and-medicaid-programs-reform-of-requirementsfor-long-term-care-facilities\#h-19. Accessed July 18, 2016.

18. Kripalani S, Jackson AT, Schnipper JL, et al. Promoting effective transitions of care at hospital discharge: A review of key issues for hospitalists. J Hosp Med. 2007;2:314-323.

19. van Walraven C, Seth R, Austin PC, et al. Effect of discharge summary availability during post-discharge visits on hospital readmission. J Gen Intern Med. 2002;17:186-192.

20. Nelson EA, Maruish ME, Axler JL. Effects of discharge planning and compliance with outpatient appointments on readmission rates. Psychiatr Serv. 2000;51(7):885-9.

21. Boxer RS, Dolansky MA, Bodnar CA, Singer ME, Albert JM, Gravenstein S. A randomized trial of heart failure disease management in skilled nursing facilities: design and rationale. J Am Med Dir Assoc. 2013;14(9):710.e5-11.

22. Anderson SL, Marrs JC, Vande Griend JP, Hanratty R. Implementation of a clinical pharmacy specialist-managed telephonic hospital discharge follow-up program in a patient-centered medical home. Popul Health Manag. 2013;16(4):235-41.

23. Horwitz LI, Moriarty JP, Chen C, Fogerty RL, Brewster UC, Kanade S, Ziaeian B, Jenq GY, Krumholz HM. Quality of discharge practices and patient understanding at an academic medical center. JAMA Intern Med. 2013;173(18):1715-22.

24. Ouslander JG, Bonner A. SNFs: Opening the Black Box. AHRQ Patient Safety Network. Available at https://psnet.ahrq.gov/webmm/case/313/ snfs-opening-the-black-box. Accessed July 18, 2016.

25. Messina FC, McDaniel MA, Trammel AC, Ervin DR, Kozak MA, Weaver CS. Improving specialty care follow-up after an ED visit using a unique referral system. Am J Emerg Med. 2013;31(10):1495-500.

26. Institute of Medicine. Crossing the quality chasm: A new health system for the 21 st century. Washington, DC: National Academy Press; 2001.

27. Transitions of Care in the Long-Term Care Continuum, Practice Guideline. Available at https://www.amda.com/tools/clinical/toccpg. pdf. Accessed July 18, 2016.

28. Guinn CC, Port CL, Zimmerman S, Gruber-Baldini AL, Kasper JD, Fleshner I, Yody B, Loome J, Magaziner J. Short-stay nursing home rehabilitation patients: transitional care problems pose research challenges. J Am Geriatr Soc. 2008;56:1940-1945.

29. Tang N, Fujimoto J, Karliner L. Evaluation of a primary care-based postdischarge phone call program: keeping the primary care practice at the center of post-hospitalization care transition. J Gen Intern Med. 2014;29(11):1513-8. 